\title{
Pavement Friction and Skid Resistance Measurement Methods: A Literature Review
}

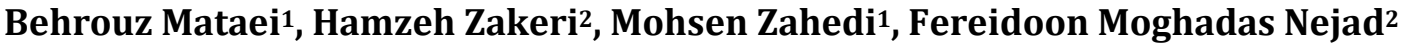 \\ ${ }^{1}$ Department of Engineering, Razi University, Kermanshah, Iran \\ ${ }^{2}$ Department of Civil and Environment Engineering, Amirkabir University of Technology, Tehran, Iran \\ Email: mataei.behrouz@stu.razi.ac.ir, h-zakeri@aut.ac.ir, zahedi@razi.ac.ir,moghadas@aut.ac.ir
}

How to cite this paper: Mataei, B., Zakeri, H., Zahedi, M. and Nejad, F.M. (2016) Pavement Friction and Skid Resistance Measurement Methods: A Literature Review. Open Journal of Civil Engineering, 6, 537-565.

http://dx.doi.org/10.4236/ojce.2016.64046

Received: July 14, 2016

Accepted: September 2, 2016

Published: September 5, 2016

Copyright $\odot 2016$ by authors and Scientific Research Publishing Inc. This work is licensed under the Creative Commons Attribution International License (CC BY 4.0).

http://creativecommons.org/licenses/by/4.0/

\begin{abstract}
Driving safety is of significance in the automobile industry and transportation systems. Pavement skid resistance has long been recognized as the most important parameter in reducing traffic accidents especially in wet conditions. The knowledge of the friction coefficient and skid resistance is very valuable information for safety enhancement of roads. Thus, it is important to find proper methods for measuring skid resistance and frictional properties of the pavement surface. There is a wide range of measurement methods and devices for measuring skid resistance. This paper presents a review on the research studies that have been done on characterization of the frictional properties of the pavement surface and discussed methods used for measurement and evaluation of texture characteristics and the strengths and weaknesses of these methods. Finally, some ideas have been suggested to develop new methods for better and proper measurement of skid resistance.
\end{abstract}

\section{Keywords}

Skid Resistance, Asphalt Pavement, Emerging Technology, Image Processing, Device

\section{Introduction}

The development of automotive technology provided an opportunity for users to drive at higher speed on roads, but such technology requires proper road conditions for higher safety acquisition. The pavement surface must put its users in a safe and comfortable condition. Traffic accidents can be the result of a combination of many factors but one of the primary safety criterions for asphalt pavements is tire-pavement interaction, and this is directly related to surface texture characteristics, which contributes to skid resistance and surface drainage. Skid resistance is one of the most important characteristics, which significantly affects the safety of driving on pavements and roads and 
has a serious effect on the accidents occurrence, especially in wet surface conditions. The low value of skid resistance, especially in wet pavement, leads to dangerous driving conditions. Since it is common engineering practice to create a highly comfortable and safe situation for users of facilities, it is obvious why complete emphasis is given to research of pavement texture characteristics. The evaluation of texture properties of the pavement surface like skid resistance was often performed with the conventional tests like sand patch tests, the British pendulum and the drainage tests. These tests are normally performed in the field after the pavement construction. Several researchers have been trying to develop different methods for the analysis of the asphalt pavement surface with respect to its skid resistance, which are faster and more accurate with lower costs.

This paper, presents a review on the research studies that have been done on characterization of the frictional properties of the pavement surface and discussed different methods used for measurement and evaluation of texture characteristics. The first section of this study summarizes the general knowledge, and research studies have been done on characterization of the frictional properties of the pavement surface.

In this study, the friction mechanism and the factors affecting frictional properties of the road surface and the microtexture and macrotexture as two important parameters contributing to pavement friction and skid resistance have been explained in detail. Additionally, the methods currently used to measure the skid resistance and their advantages and disadvantages have been discussed. In the end, some ideas and solutions have been proposed to develop new methods for texture measurement that cover the defects of current methods and receive good results.

\section{Definition of Friction}

Although there are multiple causative factors involved in highway accidents, investigations on factors influence traffic accidents, have consistently shown a link between crashes and pavement surface characteristics, such as friction and texture. Thus, for developing effective solutions to reduce potentially hazardous situations, there is a requirement for depth studies on these parameters and understanding the relationship between them [1]. Pavement surface friction is a measure of safety for driving on the road pavements and has a great role in reducing accidents especially in wet weather conditions [2]-[4]. An essential part of the vehicle-pavement interaction is friction force between the tire and the pavement surface. It gives the vehicle the ability to have safe acceleration, maneuver, corner, and stop operations [5]. The friction force developed at the contact zone between tire and pavement is called skid resistance [6]. The skid resistance is related to many factors and it is known to be a function of pavement construction materials [7] [8], pavement roughness [9], and surface conditions [10].

Friction level is influenced by various characteristics of pavement surface and the tire of the vehicle. Developing realistic models for in-situ prediction of pavement friction due to the complicated nature of the tire-pavement interaction is very difficult [3].

Developing friction between rubber tires and the pavement surface depends on many 
factors including the texture of the pavement surface, vehicle speed, and the presence of water [11]. Additionally, the characteristics of the construction materials, construction techniques, and weathering influence pavement texture [5].

Wilson and Dunn enumerated several factors that affect the tire-pavement frictional characteristics as follows [12]:

1 -Vehicle factors:

1-1-Vehicle speed;

1-2-Angle of the tire to the direction of vehicle motion;

1-3-The slip ratio;

1-4-Tire characteristics (tire tread depth, structural type, hardness, and wear).

2-Road surface and aggregate factors:

2-1-Geological properties of the surface aggregate;

2-2-Surface texture (Microtexture and Macrotexture);

2-3-Type of surface;

2-4-Age of the surface.

3-Load factors:

3-1-The equivalent number of vehicle traffic loadings;

3-2-Road geometry;

3-3-Traffic flow conditions.

4-Environmental factors:

4-1-Temperature;

4-2-Prior accumulation of rainfall, rainfall intensity, and duration;

4-3-Surface contamination.

Also Wallman and Astrom listed various factors affecting available pavement friction as shown in Table 1 [13].

In another study, Moore [14] explained the friction phenomenon between tire and pavement surface and showed adhesive and hysteresis components of frictional forces in elastomers as shown in Figure 1 [15]. A complex interaction between adhesion and hysteresis forces while sliding on wet pavement, contributes to the vehicle stopping distance. The adhesive component of friction is created by intermolecular binding or adherence at the surface level. For keeping the micro-asperities or surface irregularities of the two surfaces which are exposed to each other, together, Vander Waals or dipole forces provide an attractive force and prevent further movement [5] [16].

The adhesion as well as the shear strength, relates to the actual contact area between the tire and the pavement surface [15] [17]. Until the slip becomes critical, the adhesion friction is dominant. Typically, at a driving speed on wet pavement, the adhesion comprises two-thirds of the resistance force [18]. The hysteresis part of friction is a function of the energy loss due to bulk deformation of rubber around the asperities of the pavement surface [19]. When vehicles pass across the asperities of a rough surface pavement, the hysteresis component reflects energy loss that occurs, as the rubber is alternately compressed and decompressed [15]. 


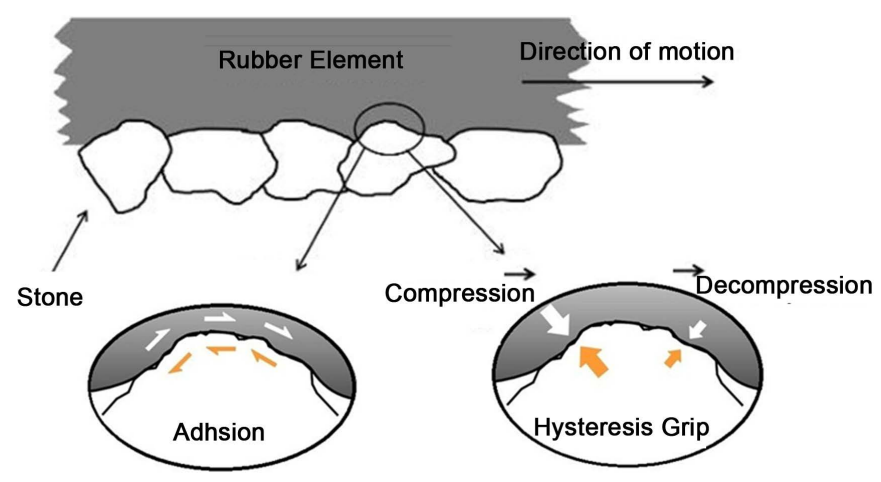

Figure 1. Schematic Plot of Hysteresis and Adhesion [15].

Table 1. Factors affecting available pavement friction [13].

\begin{tabular}{|c|c|c|c|}
\hline $\begin{array}{l}\text { Pavement Surface } \\
\text { Characteristics }\end{array}$ & $\begin{array}{l}\text { Vehicle Operating } \\
\text { Parameters }\end{array}$ & Tire Properties & Environment \\
\hline - Microtexture & - Slip speed & - Tread design and & -Wind \\
\hline - Macrotexture & -Vehicle speed & condition & -Temperature \\
\hline - Megatexture & -Braking action & - Rubber composition & -Water (rainfall, condensation) \\
\hline - Material properties & -Turning & - Inflation pressure & - Contaminants \\
\hline \multirow[t]{2}{*}{ - Temperature } & -Overtaking & • Load & -Anti-skid material (salt, sand) \\
\hline & & - Temperature & -Dirt, mud, debris \\
\hline
\end{tabular}

In addition, during a bulk deformation process, the friction force takes place at the contact area. In this process, the elastomer is affected by each macro-asperity. After passing over the asperity, the rubber returns to its initial state but this interaction causes a net loss of energy. This loss of energy contributes to the hysteresis component of friction [19].

The pavement texture and friction have been discussed in the past by several researchers. Yandell related the contribution of various texture scales to the hysteresis friction [20]-[22]. Forster [23] by using linear regression analysis proved that the texture shape, also defined by an average slope, explains friction satisfactorily. Roberts [24] showed that the material properties and the separation velocity affect the forces and the dissipation of energy between the tire and pavement surface. Kummer [25] showed that the hysteresis component of friction reaches a maximum value at high-speed sliding, while adhesion at relatively low speeds of sliding, reaches a maximum value [5].

\section{Features of the Pavement Surface}

Traffic safety and efficiency of the road system have had increasing importance for management agencies. Thus, friction evaluation has become an important tool in the management of pavement surfaces [15]. The friction properties of pavement are related to its surface texture characteristics, which are known as macrotexture and microtex- 
ture [26].

Macrotexture refers to the coarse-scale texture irregularities of the pavement surface that affects the hysteresis component of the friction. These irregularities are associated with the void area between aggregate particles. The magnitude of this component will depend on the size, shape, and distribution of coarse aggregates used in pavement construction, the nominal maximum size of aggregates and the particular construction methods used in the implementation of the pavement surface layer [6] [11] [27].

Microtexture refers to fine-scale texture irregularities in the surface of the aggregate particles that are measured at the micron scale of harshness and are known to be mainly a function of aggregate particle mineralogy [6]. Stone particles smoothness or harshness depends on these irregularities. The magnitude of microtexture depends on initial roughness of the aggregates surface and the resistance of the aggregates against the polishing action of traffic and environmental factors [6] [28]. The adhesion component of the friction is influenced by microtexture [6]. Figure 2 illustrates the microtexture and macrotexture of the pavement surface.

The definition of microtexture and macrotexture and their relation with pavement friction has been the focus of attention of several researchers for a long time. Moore [30] characterized surface texture by defining three parameters: size, interspace or density, and shape. Taneerananon and Yandell [31] showed that in the water drainage mechanism, density has minor importance compared to the two other parameters. Kokkalis and Panagouli [10] tried to explain the fractal structure of the pavement surface. They represented the relation of surface depth and density with pavement friction by developing a model. The pavement surface texture according to its size is divided into the two categories of microtexture and macrotexture (ASTM E 867). The microtexture category contains surface asperities of less than $0.5 \mathrm{~mm}$ ( $0.02 \mathrm{inch})$ in height, while the macrotexture category refers to asperities greater than $0.5 \mathrm{~mm}(0.02 \mathrm{inch})$ in size [5]. Figure 3 shows the different categories of pavement texture based on covering wavelength and different phenomena and surface characteristics related to these texture categories.

Figure 4 shows the schematic plot of microtexture and macrotexture and pavementtire friction. To prevent hydroplaning occurrence, the surface needs to have adequate macrotexture for quick dispersion of water accumulated on the surface of the pavement. Additionally, adequate macrotexture helps the development of the hysteresis component of friction which is related to energy loss due to tire deformation because

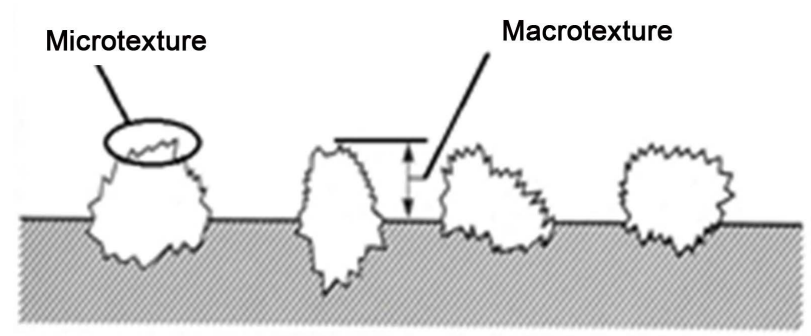

Figure 2. Micro-texture and macro-texture [29]. 


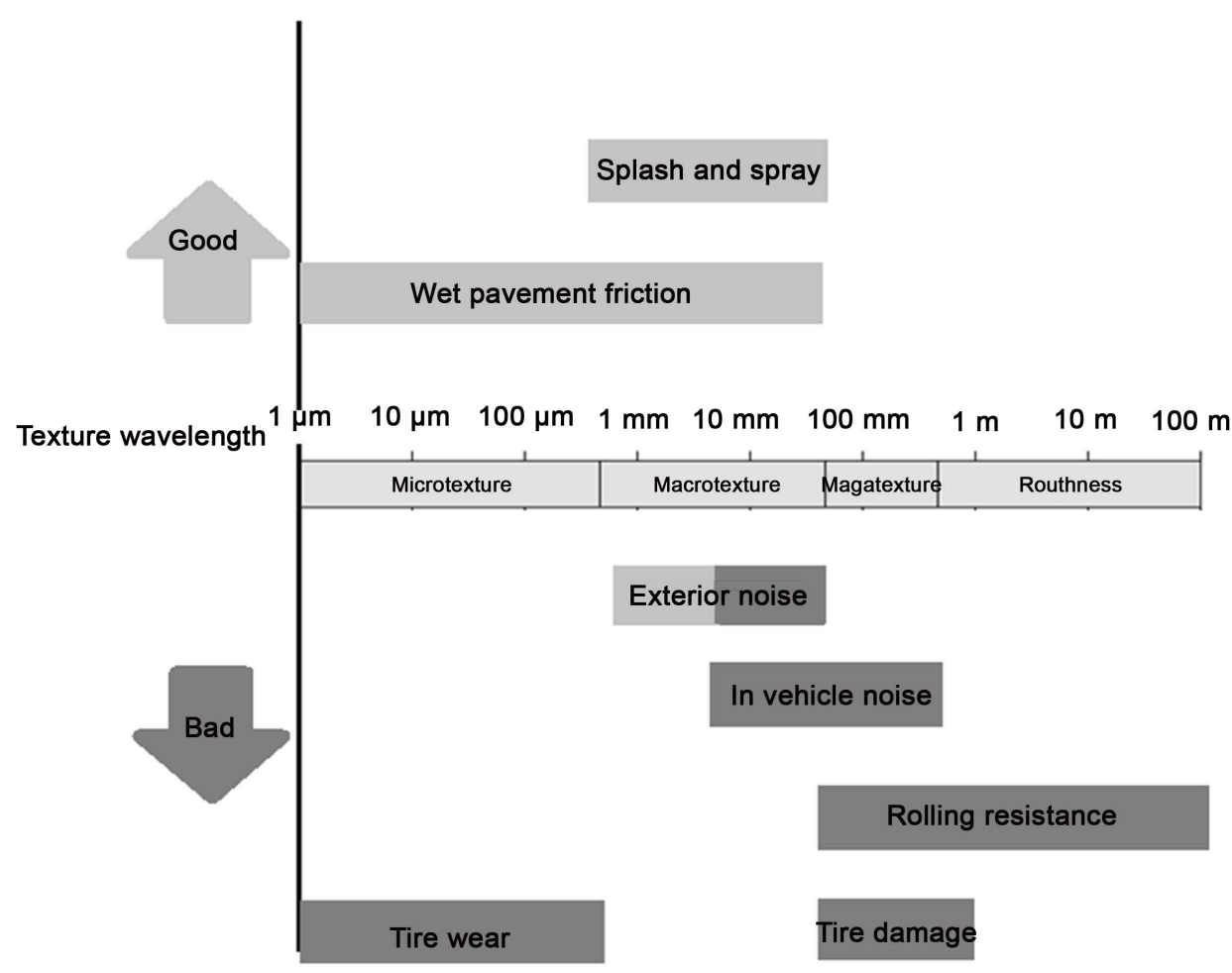

Figure 3. Pavement wavelength and surface characteristics [1].

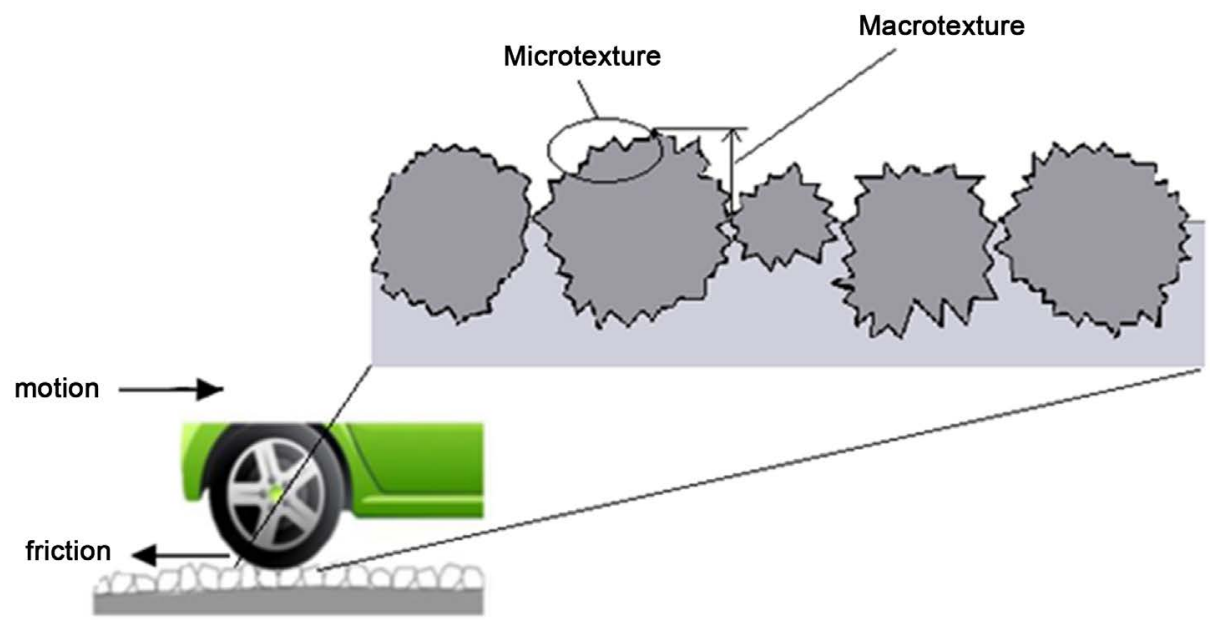

Figure 4. Schematic plot of the effect of microtexture/macrotexture on pavement friction [6].

of motion on macro asperities and consequently increases pavement friction [5] [32] [33]. Simulation of the percentage of contact points within the contact area of a tire and pavement surface could give an estimation of the macrotexture of the pavement [32]. Davis et al. [34] showed that mixture parameters have a significant influence on the ribbed tire skid resistance measurements and laser profile mean texture depth. Moreover, they reported that according to HMA mix design properties, prediction of some of the frictional properties of the wearing surface mixes is possible [34]. Bloem [35] indicated that in order to assure enough depletion of water from under the tire, an average 
texture depth of about $0.5 \mathrm{~mm}$ ( $0.02 \mathrm{inch})$ as the minimum, is required [35].

Balmer [36] showed that about ( 0.02 inch to 0.12 inch) 0.5 to over $3 \mathrm{~mm}$ change in surface texture causes a difference of $16 \mathrm{~km} / \mathrm{h}(10 \mathrm{mph})$ in speed for the initiation of hydroplaning [36] [37].

Microtexture plays a considerable role in the road-tire contact in wet surfaces. The size of microasperities has a significant trace in overcoming the thin water film. Squeezing and overcoming the thin water film present in the pavement-tire contact area and generating friction forces requires the existence of microtexture [22]. Moreover, to maintain a confident contact between tire and pavement, the microtexture has a great role to penetrate into thin water film present on the surface of the pavement [32]. The shape of micro asperities controls the drainage process [22] [31] [38]. Savkoor [39] also showed that the amplitude and number of microasperities on the surface affects the drainage of the water film between the tire and pavement [22].

Forster [32] presented a parameter in relation to microtexture based on a combination of average height and average spacing between microasperities. Ong et al. [40] showed that using materials with better microtexture reduces the chance of hydroplaning. In this research, it was shown that hydroplaning in pavements that contain coarse aggregates with high microtexture in the range of $0.2 \mathrm{~mm}$ to $0.5 \mathrm{~mm}$ occurs at 20 percent higher speed. Horne [41] also stated that it is possible to delay hydroplaning in pavements with a good microtexture [40].

A study by Pelloli [42] on five different types of surfaces showed that the relationship between friction coefficient and the water depth accumulated on the pavement surface is a function of the amount of microtexture [40]. Moore [30] reported $5 \times 10^{-3} \mathrm{~mm}$ as minimum water film thickness to be expelled by surface microasperities. Bond et al. [43] declared the same amount of magnitude by conducting visual experiments to monitor the water film between a tire and a smooth transparent plate. Bond et al. [43] showed the influenceof differences in microtexture and macrotexture of pavement surfaces on standard test tire peak brake coefficients [44]. Leu and Henry [45] explained the differences of skid resistance tests taken from different pavement surfaces based on their specific microtexture and macrotexture. However, Horne and Buhlmann [41] demonstrated the poor relation of surface friction measurements and pavement texture measurements [11] [44].

Hogervorst [18] reported that both microtexture and macrotexture of the pavement surface affects the changes of skid resistance with vehicle speed. The magnitude of skid resistance is defined by microtexture, and controlling the slope of reduction of skid resistance as speed increases is related to macrotexture. Moreover, macrotexture by reducing the friction-speed gradient and helping the drainage of water affects the skid resistance of pavements at high speed, but it has little effect at low speed. On the other hand, at low speeds, the dominant factor which defines the level of friction is microtexture [1] [46] [47] (Figure 5).

Researchers declared that the characteristics of the coarse aggregates exposed at the wearing course affect the macrotexture and microtexture of the pavement surface [5]; 


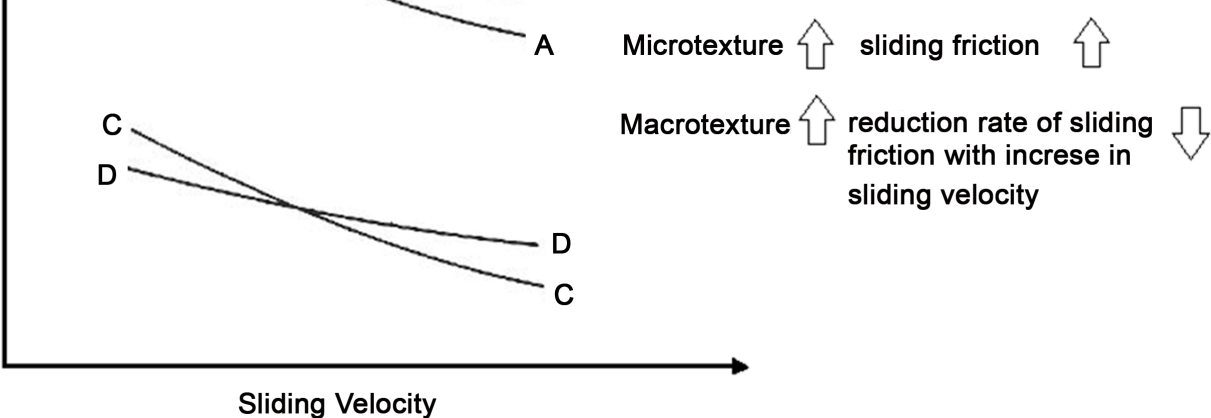

Figure 5. Schematic plot of the effect of microtexture/macrotexture on pavement friction [6].

[32]. According to microtexture and macrotexture of a pavement surface, they could be classified into four categories [10]:

- smooth and polished surface, i.e. having neither macrotexture nor microtexture.

- smooth and harsh surface, i.e. having microtexture but no macrotexture.

- rough and polished surface, i.e. having macrotexture but no microtexture.

- rough and harsh surface, i.e. having both macrotexture and microtexture.

In some researches, surface irregularities are divided into four categories: microtexture, macrotexture, megatexture and unevenness according to the scopes of wavelengths and the amplitude range shown in Figure 6. Megatexture includes major surface irregularities like roughness, cracks and potholes. It is measured in a centimeter scale and influences tire-pavement contact and decreases tire-pavement adhesion [48]. Ride comfort is highly related to megatexture [49]. Unevenness affects the safety and comfort of riding on a road due to its effect on dynamic parts of the vehicle [49].

A summary of the effect of different factors on the microtexture and macrotexture of the pavement surface is presented in Table 2. This information can be used to obtain required characteristics for pavement surface design [1].

\section{Wetting of the Pavement Surface}

The standard way of skid resistance measurement is on wet pavements. One of the most important parameters influencing skid resistance is the wet or dry condition of the pavement surface. Many researchers demonstrated that there is a relationship between accidents in wet weather conditions and pavement surface friction [13] [50]-[53]. In places where there are long intervals between precipitations, after a dry period, the number of accidents increases during the first precipitation [54]. When the pavement becomes wet, the layer of water covering the pavement acts like a lubricant and reduces the contact between the tires and the pavement surface [55] [56]. Therefore, the friction 


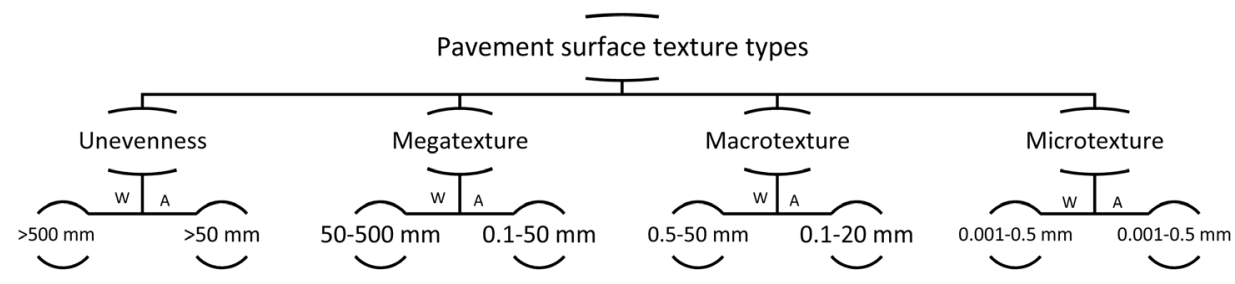

Figure 6. Types of pavement surface texture with the scope of wavelength and amplitude [49]. W: Wavelength range; A: Amplitude range.

Table 2. Factors affecting pavement micro-texture and macro-texture [1].

\begin{tabular}{|c|c|c|c|}
\hline $\begin{array}{c}\text { Pavement } \\
\text { Surface Type }\end{array}$ & Factor & Micro-Texture & Macro-Texture \\
\hline \multirow{6}{*}{ Asphalt } & Maximum aggregate dimensions & & $\mathrm{X}$ \\
\hline & Coarse aggregate types & $\mathrm{X}$ & $\mathrm{X}$ \\
\hline & Fine aggregate types & & $\mathrm{X}$ \\
\hline & Mix gradation & & $\mathrm{X}$ \\
\hline & Mix air content & & $\mathrm{X}$ \\
\hline & Mix binder & & $\mathrm{X}$ \\
\hline \multirow{6}{*}{ Concrete } & Coarse aggregate types & $\mathrm{X}$ (for exposed agg. PCC) & $\mathrm{X}$ (for exposed agg. PCC) \\
\hline & Fine aggregate types & $\mathrm{X}$ & \\
\hline & Mix gradation & & $\mathrm{X}$ (for exposed agg. PCC) \\
\hline & Texture dimensions and spacing & & $\mathrm{X}$ \\
\hline & Texture orientation & & $\mathrm{X}$ \\
\hline & Texture skew & & $\mathrm{X}$ \\
\hline
\end{tabular}

decreases and the pavement surface exhibits lower friction than the dry-pavement surface. In addition to this lubricating effect of water at high speeds, lack of drainage facility in the presence of certain depths of water film may result in hydroplaning (hydroplaning occurs when a water film builds between the tires of the vehicle and the pavement surface, leading to the loss of traction and thus disabling the vehicle from responding to actions like steering, braking or accelerating [57]), which is considered the main cause of accidents in wet weather conditions [55] [58].

Implementing corrective actions in hazardous areas can reduce the rate of these accidents. It is necessary for future safety improvements to evaluate the safety of roads and analyze the different factors affecting pavement friction. The occurrence of dynamic hydroplaning is influenced by pavement macrotexture and tires tread depth in two ways. First, the critical hydroplaning speed directly depends on these factors because they provide a pathway for water to digress from the pavement-tire contact area and delay hydroplaning. Second, the critical hydroplaning speed indirectly depends on these factors because the larger macro-texture requires more water presence to cause hydroplaning. However, the pavement surface must also have an adequate microtexture to develop good friction. Research studies have shown that a 63 percent decrease in 
wet-pavement crashes can be obtained by an increase in average pavement friction from 0.4 to 0.55 [1] [59]. Research by Kamel and Gartshore also showed 71 percent reduction in wet weather crashes in intersections and 54 percent on freeways by improving the skid resistance [1] [60]. The Organization for Economic Cooperation and Development (OECD), found a linear relationship between the slipperiness of the road surface and the accidents. Moreover, with an increase in slipperiness of the road surface, the rate of crashes increased [1] [61]. Roe et al. [62] also showed that the rate of crashes decreased with an increase in pavement friction. Wambold et al. [63] reported that wet-weather accidents have a significant relationship with the skid numbers measured with a skid trailer. The effect of wet weather conditions on road safety was also demonstrated by a study conducted in Germany, where the proportion of wet crashes was compared to pavement surface friction, as shown in Figure 7. Friction in this study was measured at a speed of $50 \mathrm{mi} / \mathrm{hr}(80 \mathrm{~km} / \mathrm{hr})$. This figure clearly shows a significant decrease in wet pavement accidents as the pavement friction increases [64].

The relationship between pavement skid resistance and crash rates and the effect of pavement friction improvement on these crash rates is also demonstrated by several researchers [64]-[68].

\section{Material Characteristics}

While most researches are focused on increasing the life span of pavement materials, there is no clear criterion for the selection and use of aggregate and mixture design to assure desirable frictional performance. In addition, available methods of evaluating aggregates for use in asphalt mixtures are mainly based on the old viewpoint of aggregate performance [69] [70].

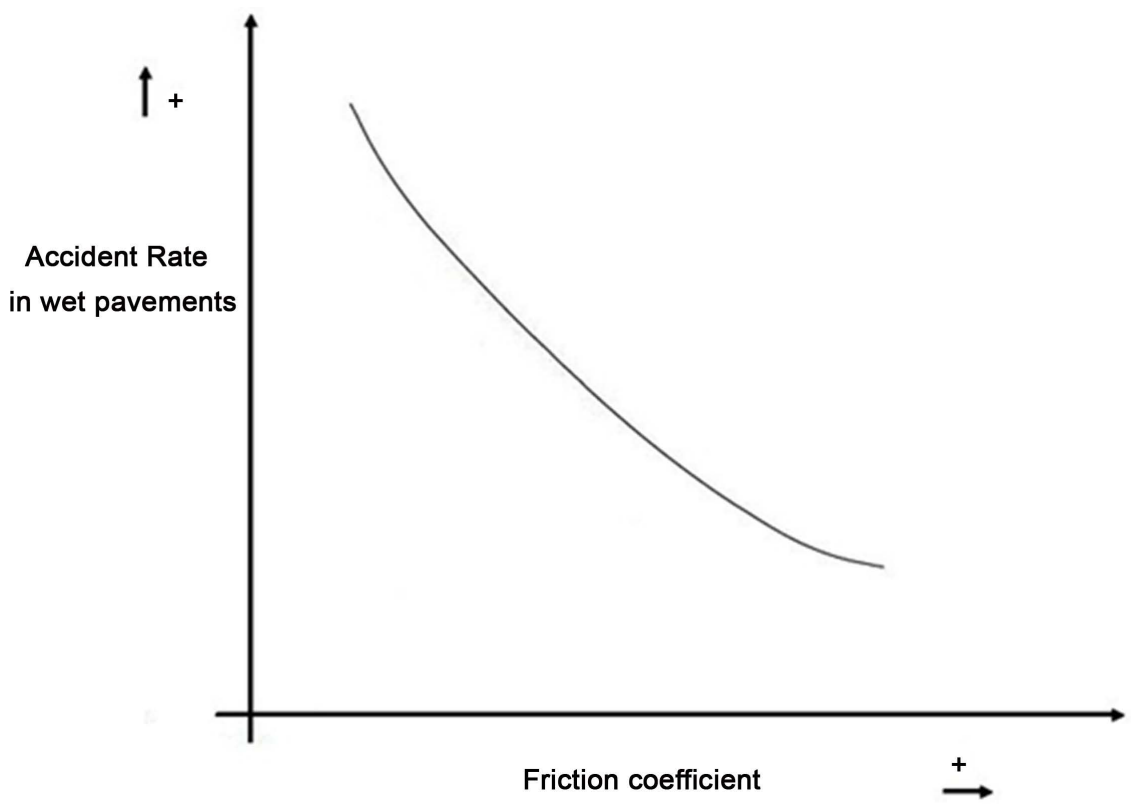

Figure 7. Relationship between crash rates in wet weather conditions and pavement surface friction [64]. 
The high correlation between pavement skid resistance and rate of accidents shows that it is required for developing a system for comprehensive material selection and mixture design. Mix designers always deal with the challenge of selection of proper aggregates. Furthermore, it is necessary to pay attention to frictional properties of aggregates and their ability to resist the polishing action of the passing traffic. Considering these important factors prevents probable additional costs for surface treatment. The cost of maintenance and rehabilitation of pavements can reduced by developing a comprehensive system for selecting aggregates based on a quantitative evaluation of the physical properties of aggregate related to pavement skid resistance. This system would consider the effects of pavement microtexture and macrotexture to propose the optimal pavement skid resistance and facilitate the selection of aggregate type and mixture design to satisfy safety requirements. To achieve this optimization, it is required to find a proper accelerated polishing method and systematic test method for measuring the frictional properties of the pavement.

The ability of aggregates to keep their texture against polishing action of traffic has long been known as a highly important requirement for its use in pavement construction [35] [71]-[76]. Coarse aggregate characteristics like angularity and resistance to wear, have a substantial role in providing sufficient skid resistance in pavements. Using hard and irregularly shaped coarse aggregates is a key to attaining and retaining the desired texture. To avoid reducing skid resistance of the asphalt surface, it is essential to implement a hard and polish-resistant coarse aggregate [35]. Fine aggregates show their significant role only when used in relatively large quantities [77]. The adhesion component of pavement friction could be highly enhanced by using Sharp, hard sand particles [18]. Aggregates, based upon their mineralogy, are polished differently in the asphalt mixture. Aggregates polish or become smoother at different rates because of their different ability to resist the polishing action of traffic [78] [79].

\section{Texture and Friction Measurement}

There are a number of test procedures and devices available to measure the skid resistance of the pavement surface. Every single of them has specific features and it is vital to know that these devices all measure slightly different parameters and hence their results cannot be compared directly but in some aspects we can compare these measurement tests. In a general classification we can divide the measurement of skid resistance into two categories:

-Field measurement;

-Portable and laboratory testers.

These measurements are also divided into other categories. Figure 8 shows the classification of measurement methods:

\subsection{Field Measurement}

Field skid resistance is generally measured by the force generated when a locked tire slides on a pavement surface [80]. These measurement methods should be precise, and 


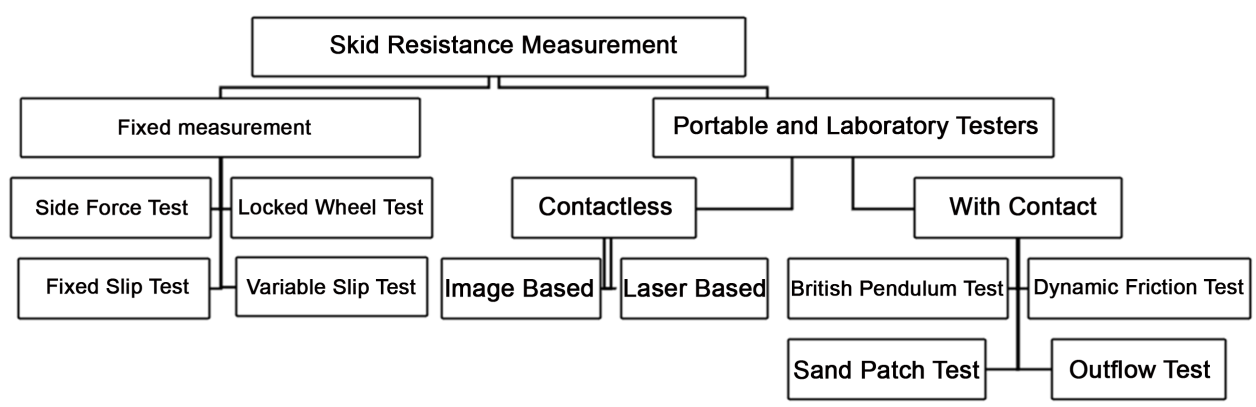

Figure 8. Classification of skid resistance measurement method.

have a high repeatability and reproducibility to reflect the real condition in the field [26]. Friction testing is comprised of applying a standard test tire to the pavement surface with a controlled wheel slip (0 to 100 percent slip) and measuring friction between the test tire and pavement surface (American society for testing and materials (ASTM) E274, E303, E503, E556, E670, E707) [44].

In the field of direct measurements, there are four main types of skid resistance measuring approaches [81]-[83]:

-Locked wheel: The friction coefficient is measured while a 100 percent slip condition is produced.

-Sideway force: The friction is measured on a rotating wheel with a yaw angle of $20^{\circ}$.

-Fixed slip: The friction is measured for wheels that are constantly slipping.

-Variable slip: Measures the friction at any desired slip.

In all methods related to locked wheel and variable slip of tires, the friction coefficient is measured on wet pavement surfaces [44].

Henry [84] found that the locked wheel method (ASTM E 274) is the most common method for pavement friction measurement in the U.S. This method aims to measure the frictional properties of the pavement surface under sudden braking conditions for a vehicle without anti-lock brakes. Unlike the side-force and fixed-slip methods, in the locked-wheel method the slip speed is equal to the vehicle speed, which means that the test wheel is locked and unable to rotate [84].

Operation speed of locked-wheel friction testers is usually between 40 and $60 \mathrm{mi} / \mathrm{hr}$ (64 and $96 \mathrm{~km} / \mathrm{hr}$ ). This test can be done with a smooth (ASTM E 524) or ribbed tire (ASTM E 501). The ribbed tire is insensitive to the thickness of the pavement surface water film and is insensitive to the pavement macro-texture, but the smooth tire is sensitive to the macro-texture of the pavement surface [4] [84]. Saito et al. [85] enumerated some of disadvantages associated with locked wheel testers:

-It is not possible to measure skid resistance continuously.

-Although Kummer and Meyer [26] showed that the cost of a locked wheel trailer is about 90 percent of other field testers, the initial and operating costs of its equipment are still high.

-The relationship between skid resistance and speed cannot be determined without repeated measurements on the pavement of the same sections of the road and different speeds because tests are conducted at only one speed. 
Other measurement methods comprise the fixed slip, variable slip, and the sideway force or cornering method. In the fixed and variable slip method, the coefficient of friction is a function of the slip of the test wheel while rolling over the pavement surface [11].

Fixed-slip devices use vehicles with anti-lock brakes to measure the friction. They maintain a constant slip, typically between 10 and 20 percent, as a vertical load is applied to the test tire [84]. These devices are more sensitive to micro-texture at low slip speeds [1].

Variable-slip devices (ASTM E1859) use a predetermined set of slip values for measuring the frictional force.

The side-force method (ASTM E670) output is a sign of the ability of vehicles to maintain control in curves. In this test the test wheel must maintain a constant angle (yaw angle) to the direction of motion [1]. The side-force method test wheel moves at an angle to the direction of vehicle motion because the critical situation for skid resistance occurs in cornering [85].

Side-force testers are sensitive to changes in the pavement microtexture but they are generally insensitive to pavement macro-texture. The two side-force measuring devices that are widely used are the Mu-Meter and the Side-Force Coefficient Road Inventory Machine (SCRIM). The ability of continuous friction measurement throughout a test section is the primary advantage of side-force measurement devices, because this ability ensures that areas with low friction are not skipped due to a sampling procedure [84].

\subsection{Portable and Laboratory Testers}

Methods explained before are categorized as field methods. Other testing methods are portable and laboratory testers. The most common portable tester is the British pendulum tester (BPT), which is specified in ASTM E303. The British pendulum tester [51] is a simple and cheap instrument used in the measurement of friction characteristics of pavement surfaces. This device can be used to measure pavement friction characteristics in the laboratory or at low speeds in the field. The BPT is easy to handle, can be used in the laboratory and in the field, but its result is only a measure of frictional property at a low speed [85].

Experience has shown that although this tester measurement is largely influenced by the microtexture of the pavement surface, the macrotexture can also affect the measurements [86]. Fwa et al. [86] and Liu et al. [87] showed that the effective factors on British pendulum measurements are the macrotexture of pavement surface and aggregate gap width, or the number of gaps between aggregates. BPT results from coarse-textured surfaces friction measuring can be misleading [4]. Other researchers also showed that the British pendulum tester exhibited unreliable behavior in coarse-textured surface measurements [88]-[90].

The DFT is a tester device that measures the friction force between the surface and three rubber pads attached to a rotating disc. The disc rotates horizontally at a linear speed of about 20 to $80 \mathrm{~km} / \mathrm{hr}$ under a constant load. The rubber pads can touch the 
pavement surface at different speeds so the DFT can measure the skid resistance at various speeds [85]. In a study, Saito et al. [85] showed that the coefficient of friction of the DFT and the British Pendulum Number (BPN) have a high correlation at each point for each measuring speed [85]. Both British pendulum and DFT device procedures are based on determining the loss in kinetic energy of a sliding pendulum or rotating disc when they are in contact with the pavement surface. Measuring friction at various speeds is an advantage for the DFT device because it is able to measure the speed dependency of the pavement friction [85].

Pavement researchers have been long concerned about measuring the pavement microtexture and macrotexture and relating these measurements to pavement skid resistance. The practice of pavement macrotexture measurement has been a common practice in recent years [84] [91]. Yandell et al. [92] declared that predicting pavement surface friction with computer models by the use of laboratory measurements is more desirable than field measurement. It is favorable to use a computer model considering that test methods are not easily repeatable and prediction methods are fast and low cost [44].

Pavement macrotexture is generally measured by a volumetric method. Essentially, in this method a known volume of a homogenous material (sand, glass beads, or grease) is spread on the pavement surface and the resulting area is measured. Mean Texture Depth (MTD) will be obtained by dividing the initial volume by the area [33] [93]. The volumetric methods are burdensome for use in routine testing [28].

The Outflow Meter Test (OFT) is another method for pavement macro texture measurement [94].

The outflow meter can be used for measuring the relative drainage ability of the pavement surface and detecting surface wear and predicting correction measures [95].

In the Outflow Meter test, a transparent vertical cylinder with a rubber ring under it, placed on the pavement surface. Then, water is allowed to flow into the pavement, and the required time for passing a determined volume of water in the transparent vertical cylinder is recorded. This time indicates the ability of the pavement surface to drain water and shows how fast water depletes from the surface. This time is reported as the outflow time and can be related to pavement macrotexture [91]. This test output is an indication of the hydroplaning potential of a surface by relating to the escape time of water beneath a moving tire. The measurement parameter, outflow time (OFT), defines the macro-texture of the pavement surface. Pavement surfaces with smooth macrotexture have high OFTs and pavement surfaces with rough macrotexture have low OFTs [1].

In the past decade, with significant advances in laser technology and in the computational power and speed and creation of small and high-speed computers, several systems are now available to measure macrotexture at traffic speeds. Various profile statistics such as the Mean Profile Depth (MPD), the overall Root Mean Square (RMS) of the profile height and other parameters that reduce the profile to a single parameter can be computed by these systems [91]. The Mini-Texture-Meter developed by British Trans- 
port and Road Research Laboratory [28], the Selcom Laser System developed by researchers at the University of Texas at Arlington [28] [96], and the noncontact high speed optical scanning technique developed by the researchers at Pennsylvania State University [28] [97] are examples of these systems. The Mini Texture Meter and the Selcom Laser System use a laser beam to scan the pavement surface and estimate pavement texture depth. The noncontact high-speed optical scanning technique uses a strobe band of light with high infrared content to generate shadowgraphs. This technique can use a vehicle moving at normal highway speeds to collect information from the pavement surface [28].

Circular Texture Meter (CTMeter) is a relatively new device for measuring MPD which was introduced in 1998 [6] [84]. The CTMeter is a laser-based device for measuring the MPD of a pavement at a static location. This device can be used in the laboratory or in the field. It measures the profile of a circle 11.2 inch $(284 \mathrm{~mm})$ in diameter or 35 inch $(892 \mathrm{~mm})$ circumference with laser equipment [91].

The profile is divided into eight segments of 4.4 inches $(111.5 \mathrm{~mm})$ and the mean depth of each segment or arc of the circle is computed according to the standard procedure of ASTM and the International Standard Organization (ISO) [91]. The Mean Profile Depth (MPD) and Root Mean Square (RMS) indices can be computed from these profiles. The MPD is a two-dimensional estimate of the three-dimensional parameter MTD [29]. The MPD represents the average of the highest profile peaks in eight individual segments comprising the circle of measurement. The RMS is a statistical value, which presents a measure of deviation of the actual data from the measured profile and a best-fit of the data from the modeled profile [98]. The CTMeter produced comparable results to the Sand Patch Test (ASTM E965). In their studies, Hanson and Prowell [99] indicated that the CTMeter has more variablity than the Sand Patch Test.

There are several methods for measurement of the microtexture [22]. A research accomplished at Pennsylvania State University showed that there is a high correlation between the zero speed intercept of the friction-speed curve of the Penn State model and the RMS of the microtexture profile height. In addition, researchers found that the BPN values have a high correlation with this parameter. Therefore, the BPN values could be considered as the substitute for microtexture measurements [45].

Observations of pictures of road stones taken by means of the Scanning Electron Microscope (SEM) showed how microtexture of the aggregates is affected by the polishing actions, as simulated in the laboratory by the British Accelerated Polishing Test [100]-[102]. It should be noted that the test results are highly sensitive and have a large variability. For the test results to be purely indicative of aggregate textures, other factors need to be controlled. Coupon curvature, the arrangement of aggregate particles in a coupon for heterogeneous materials such as gravel, the length of the contact path, and slider load have significant effects on the results, and any change in these parameters would yield misleading results [11] [103]. The degree of polishing of various aggregate types is different because the aggregates are further polished or conditioned during the slider swing [103]. 
Sengoz et al. [57] compared the results from a conventional sand patch with the ones obtained through laser scanning analysis. For the laser scanning method, a $3 \mathrm{~d}$ laser scanner including an enhanced sensor was utilized to inspect a full range of colors and depths on the selected asphalt pavement surface. The laser equipment was mounted on a portable vehicle attached to a computer. The device measures texture by means of laser light. This study was conducted on sections which were exposed to the same environment but different traffic loading conditions. The $3 \mathrm{~d}$ laser scanning produces results comparable with the ASTM E965 sand patch test. A strong relationship $\left(\mathrm{R}^{2}=0.97\right)$ is obtained between the MTD as obtained from the sand patch test and MPD as obtained from $3 \mathrm{~d}$ laser scanning. This study also demonstrated the feasibility of assessing the surface texture of the pavement by means of laser scanned image analysis. The main advantage of the utilized $3 \mathrm{~d}$ laser scanning system is acquisition time and accuracy as compared with the sand patch test and it would give an accurate and detailed assessment of pavement texture.

The application of optic or laser devices in direct measurements are gaining popularity because of their simplicity and being easy to use. Forster [23] used cameras to digitize and measure road profile images obtained from a projection device. He combined measurements of the average height and average spacing of the microtexture asperities and developed a parameter according to it. Yandell and Sawyer [21] proposed a device using almost the same measurement procedure for in-situ use. Samuels [104] used a laser sensor to directly record profiles. The laser system, with a measuring range of $6 \mathrm{~mm}$ and a spot size of around 0.1 to $0.2 \mathrm{~mm}$, was not able to detect significant differences in the microtexture of different road surfaces [22]. Improvements of new technologies in recent years lead to developing faster and more reliable measurement methods. Some new data acquisition techniques include interferometry, structured light, various $2 \mathrm{D}$ profiling methods, and the Scanning Laser Position Sensor (SLPS). Figure 9 shows different topographic data acquisition techniques operating at different target scales that could be used in pavement [44].

Interferometry and the Stylus Profiling techniques are two different methods used for topographic data measurement at scales that cover a section of the target scales for determining pavement texture [44]. Structured light and the SLPS techniques are new methods of surface topography acquisition. It is proven that these methods deal with some limitations in measuring the surface asperities in the full range of different surfaces elevations. The SLPS is a specific technique for acquiring topographic data from pavement surfaces. This device is highly portable and can be easily used for in-situ measurement [44].

Stereo photography is a historical tool for visual inspection of surface characteristics [105]. Visual inspection requires special tools for focusing and a pair of images (stereo pair), each taken at a specific angle perpendicular to the inspected surface. This technique can potentially measure the topographic features of the surface, but the precision is obviously limited to the utilized equipment. Digital scanning systems and computer algorithms have recently been developed to analyze the pictures taken from the surface 


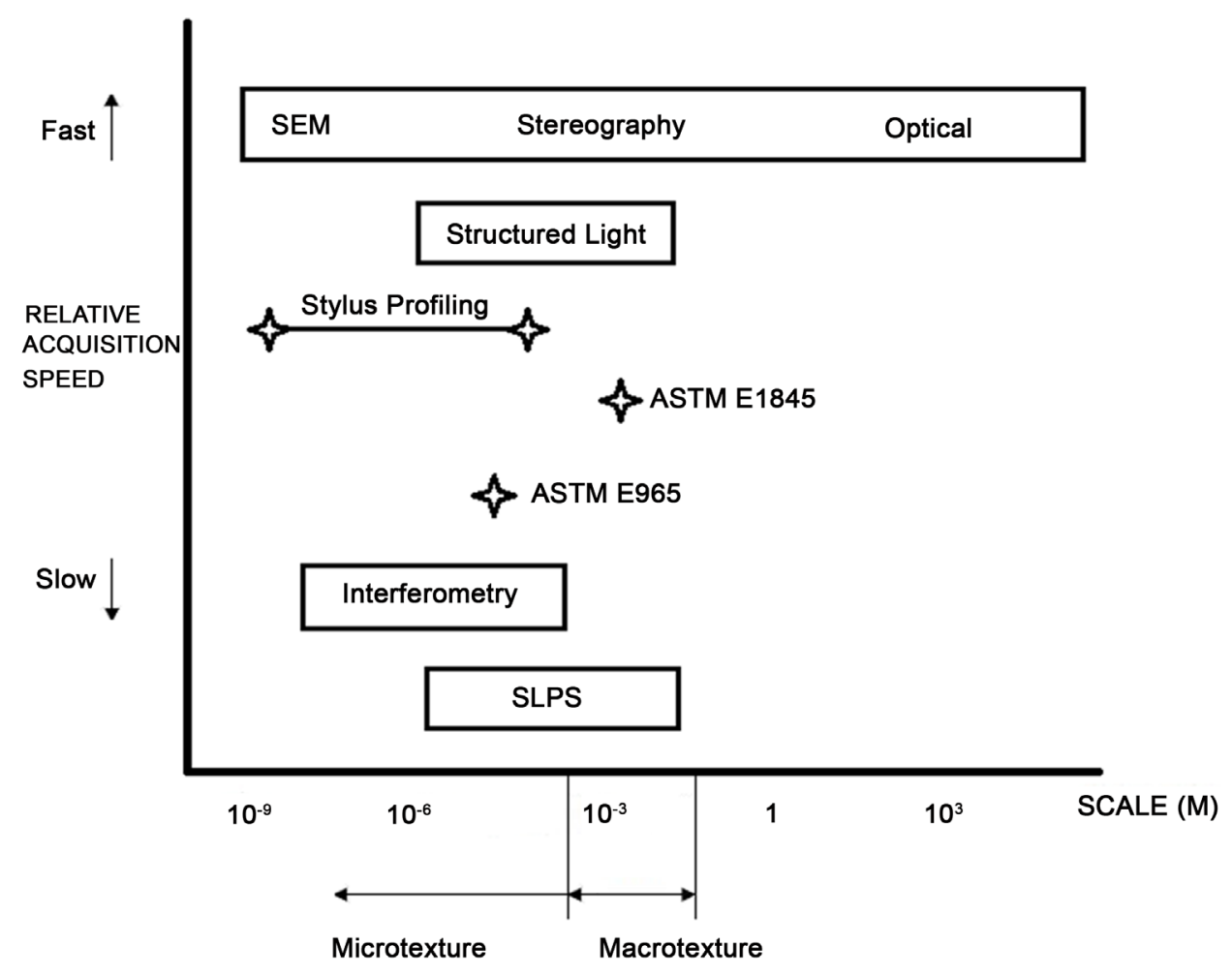

Figure 9. Different data acquisition methods [44].

texture [44]. Anis et al. [9] proposed a methodology based on the photometric stereovision technique and a surface photometric model and show that it is feasible to assess surface texture characteristics by means of image analysis.

Image processing is another method for road surface texture measurement. In 1970, Schonfeld developed the idea of employing image processing techniques for road surface macro texture [106]. Schonfeld [105] presented a method for the Ontario Transportation Department based on subjective assessment using photos taken from the pavement. He used road stereo photography to define microtexture characteristics. The attributed characteristics were related to microasperity size and shape. This method is a subjective and global method [22].

In addition, recent interest in image processing techniques for quantification of macrotexture has arisen, using the fast fourier transform (FFT), autocorrelation function and wavelets transform (mainly using FFT). The study by Gransberg et al. [107] involved the analysis of road surfaces by image processing using the fast Fourier transform. It was observed that road surfaces with good conditions display a higher maximum FFT magnitude value than deteriorating roads. Pidwerbesky [108] found that FFT output from the images of pavement surfaces have a high correlation with a coefficient of determination of up to 0.93 with sand patch test results.

The aggregate imaging system (AIMS) introduced by Masad et al. [109] is one of the recent methods measuring the aggregate texture directly by use of a microscope and a digital image processing technique [109]. This method is an important development in 
texture measurement methods, which has the ability to rapidly measure physical characteristics of the aggregate. This advanced technology consists of a computer-automated video system that directly analyzes texture, angularity and the shape of aggregates. Victor et al. [110] compared the results obtained by conventional tests and the aggregate image measurement system (AIMS) for measuring texture characteristics of aggregates and HMAs, and in relation to the microtexture of field asphalt samples, AIMS results presented a good correlation with the results from the British pendulum.

\section{Discussion}

Pavement management system (PMS) in different phases needs accurate information for proper functioning and making correct decisions. Thus, it is important to find proper methods for measuring texture characteristics of the pavement surface. As has been mentioned in previous sections, there are various methods and devices for measuring and evaluating pavement texture characteristics like skid resistance. This paper reviewed methods and devices used for measuring skid resistance and researches accomplished about different aspects of these methods and devices. All of these methods have different specifications and particular advantages and disadvantages. This section discussed the strengths and weaknesses of these methods and their superiority compared with each other.

In field measurement methods, the Locked wheel test is a well developed method with user friendly systems which is relatively simple and not time consuming but it is limited and it can be used only on straight segments and can miss slippery spots because of its intermittent measurements.

The side force test presents continuous measurement throughout a test pavement section and has superiority because it can be used in straight sections, curves and steep grades. This method is sensitive to road irregularities like cracks and potholes which can destroy tires quickly.

The fixed slip test has the ability to collect high resolution friction data continuously and can be used in network-level or project level friction monitoring. This method can be used only on a straight segment. Fixed slip devices take reading at a specified slip speed and their speeds do not always coincide with the critical slip speed value. This method needs large amounts of water in a continuous method.

Various slip tests can be used for field testing on straight and curved segments and continuously provide any desired fixed or variable slip friction results. This measurement device is large and complex with high maintenance costs and complex data processing and analysis needs. This method needs large amounts of water in continuous mode.

In the field of portable and laboratory testers, the British pendulum tester is used worldwide as a measurement device of friction and texture. It is portable, very simple and suitable for both laboratory and field evaluation. This device can be used to measure both longitudal and lateral pavement tire friction. Weaknesses of this method are also a variable quality of results. Traffic control is required and it does not always si- 
mulate pavement tire characteristics. This device collects only spot measurement and cannot be used for network evaluation. The testers' results can also be affected by operator procedures and wind effects.

The dynamic friction tester can be used for field and laboratory testing. It provides good repeatability and reproducibility and is unaffected by operators or wind. It also provides high speed values of friction coefficient. This tester needs traffic control similar to BPT and does not always simulate pavement tire characteristics, collects only spot measurement and cannot be used for network evaluation.

The sand patch method is a simple method and needs inexpensive equipment. It is widely used for texture measuring. This method is slow and requires lane closure and represents the evaluation of only macrotexture of a small area. Results of this test are very sensitive to operator variability. The outflow meter, similar to a sand patch test, is a simple method and needs inexpensive equipment. It provides an indication of hydroplaning potential in wet weather. This method is slow and requires lane closure. It only represents a small area of the pavement surface.

The circular texture meter is a repeatable method that is independent of operators, but this method is a little slow and requires lane closure that also presents a small surface area. AIMS is a descriptive, rapid and automated method. It provides detailed information on all sizes of paving aggregates. In addition, the capability of measuring the texture of coarse aggregates has been tied to the rutting potential of asphalt mixtures and improving the friction characteristics of asphalt wearing. In addition, image based methods generally have disadvantages due to the need for large data storage capacity.

In an overall state, for prevention of traffic interruption, it is recommended that the method does not require traffic control and lane closure, locked wheels, side forces, fixed and variable slip tests do not need traffic control, while other methods need traffic control. Due to their laser equipment, AIMS and the circular texture meter have an advantage over other methods because of their contactless measurement. Table 3 and Table 4 show an overview of methods and devices mentioned in this paper.

\section{Conclusions}

There are numerous methods and devices for measuring pavement surface texture characteristics. Every single one of these measurement methods has specific weaknesses that cause restrictions and reduce the popularity of these methods. This paper discussed all aspects of the methods and their strengths and weaknesses. To develop new methods in the future without weaknesses of the present methods, it is necessary to deeply scrutinize these methods.

One of these weaknesses is being time consuming and requiring a long time for test operation. The British pendulum, dynamic friction, outflow test, sand patch test and circular texture meter are slow tests that need lane closure and traffic control during their measurement due to their low speed of measurement. Some of these devices have restrictions because they are not able to measure pavement texture characteristics in some places with special circumstances. The locked wheel tester cannot be used on 
Table 3. Overview of pavement surface texture test methods.

\begin{tabular}{|c|c|c|c|c|}
\hline Test method & $\begin{array}{l}\text { Associated } \\
\text { standard }\end{array}$ & Measurement index & Strength & Weakness \\
\hline Locked-wheel & $\begin{array}{l}\text { ASTM } \\
\text { E } 274\end{array}$ & $\begin{array}{l}\text { The Coefficient of } \\
\text { friction }(\mu) \text { is computed } \\
\text { by measuring the resistive } \\
\text { drag force and the } \\
\text { wheel load applied } \\
\text { to the pavement. } \\
\text { Friction is reported } \\
\text { as friction number (FN) } \\
\text { or skid number (SN). }\end{array}$ & $\begin{array}{l}\text {-It contains user friendly } \\
\text { systems with relatively } \\
\text { simple and non-time } \\
\text { consuming performance. }\end{array}$ & $\begin{array}{l}\text {-It cannot be used on Curves, T-sections } \\
\text { or Roundabouts. } \\
\text {-It might miss slippery sections. } \\
\text {-Continuous measurement of skid resistance is } \\
\text { not possible due to its intermittent performance. } \\
\text {-Its test equipment has high primary } \\
\text { and operating costs. } \\
\text {-Determination of speed dependency } \\
\text { of skid resistance } \\
\text { can only be performed by repeated measurements. }\end{array}$ \\
\hline Side-force & $\begin{array}{l}\text { ASTM } \\
\text { E } 670\end{array}$ & $\begin{array}{l}\text { The Mu Number, }(\mathrm{MuN}) \\
\text { or the sideways force } \\
\text { coefficient, (SFC) is } \\
\text { computed by measuring } \\
\text { the average of the side } \\
\text { force perpendicular } \\
\text { to the plane of rotation. }\end{array}$ & $\begin{array}{l}\text {-Skid condition is like the } \\
\text { fixed slip device, } \\
\text { relatively well controlled. } \\
\text {-It can be used on straight } \\
\text { sections and curves, } \\
\text { T-sections or Roundabouts. } \\
\text {-It performs continuous } \\
\text { measurement throughout } \\
\text { a test pavement section. }\end{array}$ & $\begin{array}{l}\text {-It is very sensitive to road potholes, cracks, etc. } \\
\text { and these defects can destroy tires quickly. } \\
\text {-Mu-Meter is not a universal test rig and is often } \\
\text { used for airports in the U.S. }\end{array}$ \\
\hline Fixed slip & Various & $\begin{array}{l}\text { Coefficient of Friction, } \\
(\mu) \text { is computed by } \\
\text { measuring the } \\
\text { resistive drag force } \\
\text { and the wheel load } \\
\text { applied to the pavement. } \\
\text { the Friction } \\
\text { is reported as FN. }\end{array}$ & $\begin{array}{l}\text {-It presents Continuous } \\
\text { measurement. } \\
\text {-High resolution } \\
\text { friction data can } \\
\text { be collected. } \\
\text { It can be used for network } \\
\text { and project level } \\
\text { friction monitoring. }\end{array}$ & $\begin{array}{l}\text {-The slip speed of this device especially on snow } \\
\text { covered surfaces does not always coincide with } \\
\text { the critical slip speed value. } \\
\text {-This device needs large amounts of water } \\
\text { for continuous measurement. }\end{array}$ \\
\hline $\begin{array}{c}\text { British } \\
\text { pendulum } \\
\text { test }\end{array}$ & $\begin{array}{l}\text { ASTM } \\
\text { E303 }\end{array}$ & $\begin{array}{l}\text { The British pendulum } \\
\text { tester provides British } \\
\text { Pendulum Number (BPN) } \\
\text { based on the return } \\
\text { height of pendulum, } \\
\text { after a low speed sliding } \\
\text { contact with the } \\
\text { pavement surface. }\end{array}$ & $\begin{array}{l}\text {-The British Pendulum skid } \\
\text { tester is probably the most } \\
\text { widespread skid resistance } \\
\text { measurement equipment } \\
\text { in the world. } \\
\text {-Can be used for both field } \\
\text { and laboratory evaluation. } \\
\text {-This device is highly } \\
\text { portable and easy to handle. }\end{array}$ & $\begin{array}{l}\text {-It only measures a frictional property of } \\
\text { surface at a low speed. } \\
\text {-It exhibited unreliable behavior when tested } \\
\text { on surfaces with coarse texture. } \\
\text {-BPN has a large variability and operator } \\
\text { procedures and wind can have impact on it. } \\
\text {-This test needs traffic control and lane closure. } \\
\text {-It cannot be used for network evaluation } \\
\text { because of its spot measurement. }\end{array}$ \\
\hline
\end{tabular}




\section{Continued}

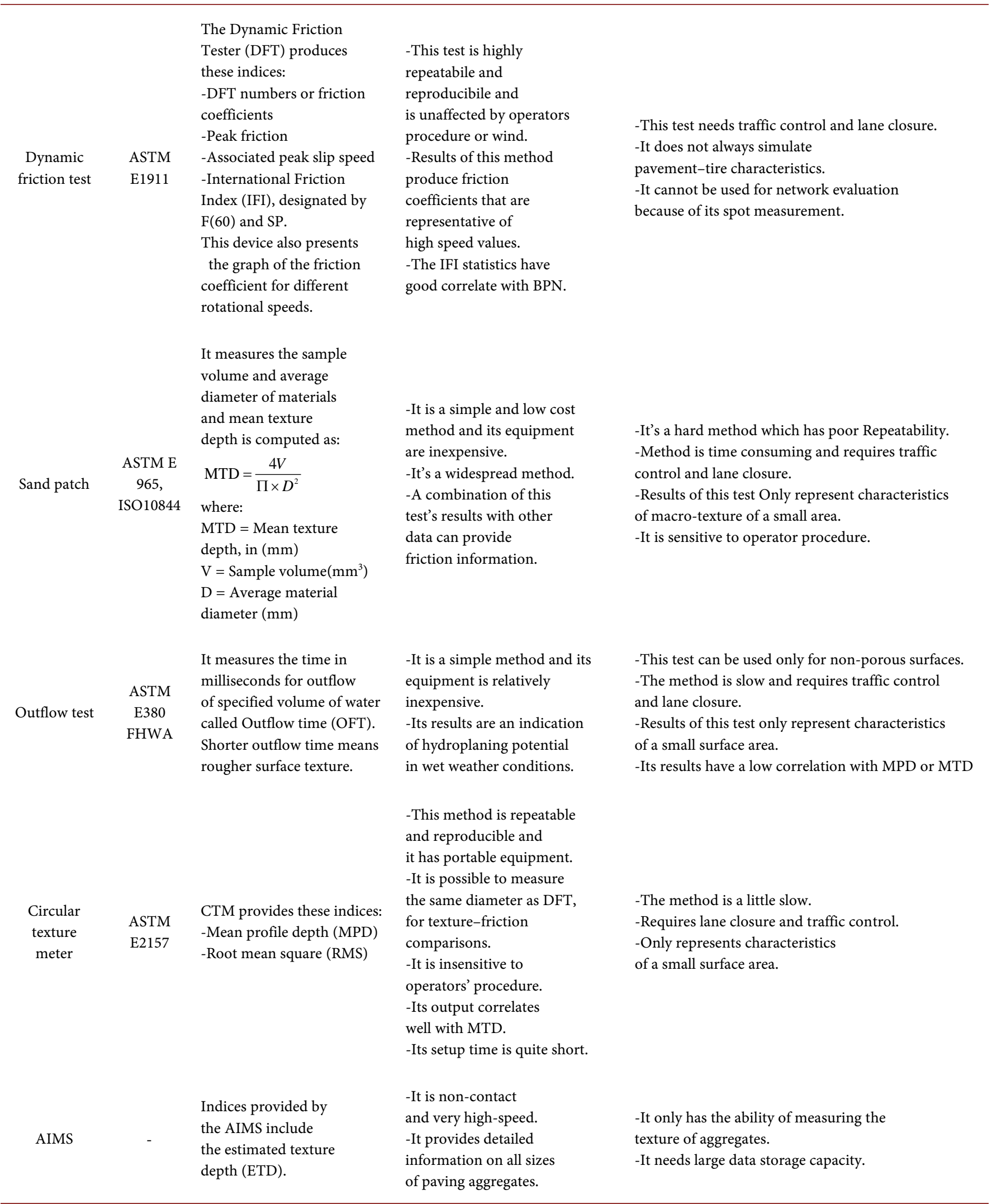


Table 4. Overview of pavement surface texture test methods.

\begin{tabular}{cccccc}
\hline Test method & Contact & Destructive & $\begin{array}{c}\text { Requiring } \\
\text { traffic control }\end{array}$ & $\begin{array}{c}\text { Requiring } \\
\text { a software }\end{array}$ & $\begin{array}{c}\text { Wet pavement } \\
\text { friction }\end{array}$ \\
\hline Locked wheel test & YES & YES & NO & NO & YES \\
Side-force & YES & YES & NO & NO & YES \\
Fixed slip & YES & YES & NO & NO & YES \\
Variable slip & YES & YES & NO & NO & YES \\
British pendulum test & YES & YES & YES & NO & NO \\
Dynamic friction test & YES & YES & YES & NO & NO \\
Sand patch & YES & NO & YES & NO & NO \\
Outflow test & YES & NO & YES & NO & YES \\
Circular texture meter & NO & NO & YES & YES & NO \\
AIMS & NO & NO & NO & YES & NO \\
\hline
\end{tabular}

Curves, T-sections or Roundabouts. The side force tester is very sensitive to road potholes, cracks, etc. and implementing this test in places with these defects can quickly destroy tires. In fixed slip devices, the slip speed on snow covered surfaces does not always coincide with the critical slip speed value. The British pendulum test exhibited unreliable behavior when tested on surfaces with coarse texture and the outflow test can be used only for non-porous surfaces.

The ability of continuous measurement is an advantage for measurement methods, the locked wheel tester and portable and laboratory testers are deprived of this ability. It is favorable to use methods with low operation and equipment costs, methods such as the locked wheel test and variable slip test have high primary and operating costs. Determination of speed dependency of skid resistance is another good ability for a measuring device. The locked wheel method can only perform it by repeated measurements. The British pendulum tester only measures a frictional property of surface at a low speed.

Selection of a model that can be used for network and project level friction measurement is more favorable. The British pendulum tester and dynamic friction tester cannot be used for network evaluation because of their spot measurement. The circular texture meter, outflow and sand patch test also have this restriction.

As mentioned previously, the standard method of skid resistance measurement is a method which evaluates surface texture in wet conditions. The wet or dry condition of the pavement surface is an important parameter influencing skid resistance. Methods such as the British pendulum test, dynamic friction and sand patch do not have the ability to evaluate pavement characteristics in wet conditions.

Present methods measure the friction characteristics and skid resistance in the direction of motion and perpendicular to it. Regarding the critical direction of skid resistance, it may occur in any diagonal direction, and it is necessary to develop a method 
which considers the critical direction for measuring skid resistance. The present measurement devices like the British pendulum do not consider this critical direction of skid resistance.

Methods like variable slip methods need complicated data processing and analysis in their measurement process. Measurement methods must also be insensitive to operator procedure and environmental circumstances. The sand patch test is sensitive to the operator procedure and the British pendulum is also affected by operator procedure and wind.

With regard to the weaknesses mentioned for the present methods used for texture measurement, it is necessary to innovate new methods that do not have these weaknesses. New methods must be high speed methods which produce the results in minimum possible time and do not need control of traffic and lane closure. These methods must perform the evaluation of friction on wet conditions and be able to measure skid resistance and frictional characteristics in a critical direction. The methods must have low initial and equipment costs. They must use simple data analyses in their measurement procedure. It is necessary to develop a method with the ability to use texture measurement at both network and project levels. These methods must produce continuous measurement and be applicable in all conditions.

For this purpose and with regard to the development of new technologies in engineering sciences, researchers must utilize these technologies to present new methods and create detailed indicators for pavement texture and friction characteristics.

\section{Future Work}

In this section some ideas have been proposed to develop new methods for measuring texture and frictional characteristics of pavement surface in the future.

Different pavement surfaces can show different light reflection based on their texture characteristics. It seems that worn texture which has lower microtexture has higher light reflection. As a future work, a method can be developed which evaluates pavement texture characteristics based on different light reflection of surfaces.

It also seems that the heat of the pavement surface is different with regard to its texture. On the other hand, the heat of pavement surfaces with different texture characteristics is also different. So a method can be developed which produces indices for pavement texture based on the heat of its surface.

Sonic methods can also be used for texture measurement. It can be expected that pavements with different surface and aggregate textures exhibit different behavior when confronted with implementing sonic techniques and this difference can be used to develop indices for pavement surface texture.

To develop a method for both network and project level measurement, finding a method which uses satellite images of the surface of roads may produce good results.

Replacing traffic cameras in intersections which are susceptible places with high resolution cameras and implementing image processing techniques to produce frictional indices for critical directions is another proposed idea for future works. 


\section{References}

[1] Hall, J.W., et al. (2009) Guide for Pavement Friction. National Cooperative Highway Research Program, Transportation Research Board of the National Academies.

[2] Council, F.M., et al. (1980) Accident Research Manual.

[3] Li, S., Zhu, K., Noureldin, S. and Harris, D. (2005) Identifying Friction Variations with the Standard Smooth Tire for Network Pavement Inventory Friction Testing. Transportation Research Record: Journal of the Transportation Research Board, 1905, 157-165.

[4] Lee, S.-W., Rhee, S.-K. and Chon, S.-J. (2005) A Study for Decreasing Rate of Skid Resistance of Tinned Concrete Pavement Based on The LTPP Data. Journal of the Korean Society of Civil Engineers, 25, 85-85.

[5] Dewey, G.R., et al. (2001) Aggregate Wear and Pavement Friction. Transportation Research Board, Annual Meeting, Washington DC, 7-11 January 2001, CD-ROM, 17 p.

[6] Noyce, D.A., et al. (2005) Incorporating Road Safety into Pavement Management: Maximizing Asphalt Pavement Surface Friction for Road Safety Improvements. Draft Literature Review and State Surveys, Midwest Regional University Transportation Center (UMTRI), Madison.

[7] Asi, I.M. (2007) Evaluating Skid Resistance of Different Asphalt Concrete Mixes. Building and Environment, 42, 325-329. http://dx.doi.org/10.1016/j.buildenv.2005.08.020

[8] Chiu, C.-T. (2008) Use of Ground Tire Rubber in Asphalt Pavements: Field Trial and Evaluation in Taiwan. Resources, Conservation and Recycling, 52, 522-532. http://dx.doi.org/10.1016/j.resconrec.2007.06.006

[9] Slimane, A.B., Khoudeir, M., Brochard, J. and Do, M.-T. (2008) Characterization of Road Microtexture by Means of Image Analysis. Wear, 264, 464-468. http://dx.doi.org/10.1016/j.wear.2006.08.045

[10] Kokkalis, A.G. and Panagouli, O.K. (1998) Fractal Evaluation of Pavement Skid Resistance Variations. I: Surface Wetting. Chaos, Solitons \& Fractals, 9, 1875-1890. http://dx.doi.org/10.1016/S0960-0779(97)00138-0

[11] Masad, E., et al. (2009) Predicting Asphalt Mixture Skid Resistance Based on Aggregate Characteristics. Transportation Research Record Journal of the Transportation Research Board, 2104, 24-33.

[12] Wilson, D.J. and Dunn, R. (2005) Analyzing Road Pavement Skid Resistance. ITE 2005 Annual Meeting and Exhibit Compendium of Technical Papers, Melbourne, 7-10 August 2005, $16 \mathrm{p}$.

[13] Wallman, C.-G. and Åström, H. (2001) Friction Measurement Methods and the Correlation between Road Friction and Traffic Safety: A Literature Review.

[14] Moore, D.F. (1972) The Friction and Lubrication of Elastomers. Vol. 9, Pergamon, Oxford.

[15] Choubane, B., Holzschuher, C. and Gokhale, S. (2004) Precision of Locked-Wheel Testers for Measurement of Roadway Surface Friction Characteristics. Transportation Research Record: Journal of the Transportation Research Board, 1869, 145-151.

[16] Persson, B.N. (2000) Sliding Friction: Physical Principles and Applications. Vol. 1, Springer Science \& Business Media, Berlin. http://dx.doi.org/10.1007/978-3-662-04283-0

[17] Zimmer, R., Choubane, B. and Holzschuher, C. (2003) Friction Testing Method for OpenGrated Steel Bridge Decks. Transportation Research Record: Journal of the Transportation Research Board, 1860, 137-143.

[18] Hogervorst, D. (1974) Some Properties of Crushed Stone for Road Surfaces. Bulletin of the 
International Association of Engineering Geology_Bulletin de l'Association Internationale de Géologie de l'Ingénieur, 10, 59-64.

[19] Lindner, M., et al. (2004) Experimental and Analytical Investigation of Rubber Friction. Safety, 200, 300.

[20] Yandell, W. (1971) A New Theory of Hysteretic Sliding Friction. Wear, 17, 229-244. http://dx.doi.org/10.1016/0043-1648(71)90027-5

[21] Yandell, W. and Sawyer, S. (1994) Prediction of Tire-Road Friction from Texture Measurements. Transportation Research Record, No. 1435, 86-91.

[22] Do, M.-T., Zahouani, H. and Vargiolu, R. (2000) Angular Parameter for Characterizing Road Surface Microtexture. Transportation Research Record: Journal of the Transportation Research Board, 1723, 66-72.

[23] Forster, S.W. (1981) Aggregate Microtexture: Profile Measurement and Related Frictional Levels.

[24] Roberts, A. (1988) Rubber Adhesion at High Rolling Speeds. Journal of Natural Rubber Research, 3, 239-260.

[25] Kummer, H. (1966) Unified Theory of Rubber and Tire Friction. Engineering Research Bulletin B -94, The Pennsylvania State University, 100-101.

[26] Kummer, H. and Meyer, W. (1963) Penn State Road Surface Friction Tester as Adapted to Routine Measurement of Pavement Skid Resistance. Road Surface Properties, 42nd Annual Meeting, 7-11 January 1963, 1-31.

[27] Roberts, F., et al. (1996) Hot Mix Asphalt Materials, Mixture Design, and Construction. Vol. 8, National Asphalt Pavement Association, Research and Education Foundation, Lanham.

[28] Jayawickrama, P., Prasanna, R. and Senadheera, S. (1996) Survey of State Practices to Control Skid Resistance on Hot-Mix Asphalt Concrete Pavements. Transportation Research Record: Journal of the Transportation Research Board, 1536, 52-58.

[29] Flintsch, G., de León, E., McGhee, K. and AI-Qadi, I. (2003) Pavement Surface Macrotexture Measurement and Applications. Transportation Research Record: Journal of the Transportation Research Board, 1860, 168-177.

[30] Moore, D.F. (1975) The Friction of Pneumatic Tyres. Eisevier, Amsterdam.

[31] Taneerananon, P. and Yandell, W. (1981) Microtexture Roughness Effect on Predicted Road-Tyre Friction in Wet Conditions. Wear, 69, 321-337. http://dx.doi.org/10.1016/0043-1648(81)90322-7

[32] Forster, S.W. (1989) Pavement Microtexture and Its Relation to Skid Resistance. Transportation Research Record, No. 1215, 151-164.

[33] Ergun, M., Iyinam, S. and Iyinam, A.F. (2005) Prediction of Road Surface Friction Coefficient Using Only Macro- and Microtexture Measurements. Journal of Transportation Engineering, 131, 311-319. http://dx.doi.org/10.1061/(ASCE)0733-947X(2005)131:4(311)

[34] Davis, R., et al. (2002) Effect of Wearing Surface Characteristics on Measured Pavement Skid Resistance and Texture. 81 st Transportation Research Board Annual Meeting, Washington DC, 13-17 January 2002, 12-17.

[35] Bloem, D.L. (1971) Skid-Resistance-The Role of Aggregates and Other Factors. National Sand \& Gravel Assoc Circulars.

[36] Balmer, G.G. (1978) Pavement Texture: Its Significance and Development. Transportation Research Record, No. 666, 1-6. 
[37] Stroup-Gardiner, M., Studdard, J. and Wagner, C. (2004) Evaluation of Hot Mix Asphalt Macro- and Microtexture. Journal of Testing and Evaluation, 32, 7-16. http://dx.doi.org/10.1520/JTE10861

[38] Rhode, S. (1976) On the Effect of Pavement Microtexture and Thin Film Traction. International Journal of Mechanical Sciences, 18, 95-101. http://dx.doi.org/10.1016/0020-7403(76)90057-6

[39] Savkoor, A. (1991) Paper VIII (iii) Tribology of Tyre Traction on Dry and Wet Roads. Tribology Series, 18, 213-228. http://dx.doi.org/10.1016/S0167-8922(08)70137-8

[40] Ong, G., Fwa, T. and Guo, J. (2005) Modeling Hydroplaning and Effects of Pavement Microtexture. Transportation Research Record: Journal of the Transportation Research Board, 1905, 166-176.

[41] Horne, W.B. (1977) Status of Runway Slipperiness Research. Transportation Research Record, 624, 95-121.

[42] Pelloli, R. (1977) Road Surface Characteristics and Hydroplaning. Transportation Research Record, 624, 27-32.

[43] Bond, R., et al. (1976) Tyre/Road Surface Interaction. Highway Engineer, 23, 11-20 (Analytic)

[44] Johnsen, W.A. (1997) Advances in the Design of Pavement Surfaces. Worcester Polytechnic Institute.

[45] Leu, M. and Henry, J. (1978) Prediction of Skid Resistance as a Function of Speed from Pavement Texture Measurements. Transportation Research Record, No. 666, 7-13.

[46] Rose, J.G., Gallaway, B.M. and Hankins, K.D. (1970) Macrotexture Measurement and Related Skid Resistance at Speeds from 20 to 60 Miles per Hour. Highway Research Record, No. 341, 33-45.

[47] Gallaway, B.M., Rose, J.G. and Schiller Jr., R. (1972) The Relative Effects of Several Factors Affecting Rainwater Depths on Pavement Surfaces. Highway Research Record, No. 396, 5971.

[48] Panagouli, O. and Kokkalis, A. (1998) Skid Resistance and Fractal Structure of Pavement Surface. Chaos, Solitons \& Fractals, 9, 493-505. http://dx.doi.org/10.1016/S0960-0779(97)00085-4

[49] Kotek, P. and Kováč, M. (2015) Comparison of Valuation of Skid Resistance of Pavements by Two Device with Standard Methods. Procedia Engineering, 111, 436-443. http://dx.doi.org/10.1016/j.proeng.2015.07.113

[50] Rizenbergs, R.L., Burchett, J.L. and Napier, C.T. (1972) Skid Resistance of Pavements [July 1972].

[51] Giles, C., Sabey, B.E. and Cardew, K. (1965) Development and Performance of the Portable Skid Resistance Tester. Rubber Chemistry and Technology, 38, 840-862. http://dx.doi.org/10.5254/1.3535703

[52] McCullough, B.F. and Hankins, K. (1966) Skid Resistance Guidelines for Surface Improvements on Texas Highways. Highway Research Record, No. 131, 204-217.

[53] Gandhi, P.M., Colucci, B. and Gandhi, S.P. (1991) Polishing of Aggregates and WetWeather Accident Rates for Flexible Pavements. Transportation Research Record, No. 1300, 71-79.

[54] Tyfour, W. (2009) Tire skid Resistance on Contaminated Wet Pavements. Jordan Journal of Mechanical and Industrial Engineering, 3, 119-124.

[55] Flintsch, G.W., Luo, Y. and Al-Qadi, I. (2005) Analysis of the Effect of Pavement Tempera- 
ture on the Frictional Properties of Flexible Pavement Surfaces. 84th Transportation Research Board Annual Meeting, Washington DC, 9-13 January 2005.

[56] Jayawickrama, P. and Thomas, B. (1998) Correction of Field Skid Measurements for Seasonal Variations in Texas. Transportation Research Record: Journal of the Transportation Research Board, 1639, 147-154.

[57] Sengoz, B., Topal, A. and Tanyel, S. (2012) Comparison of Pavement Surface Texture Determination by Sand Patch Test and 3D Laser Scanning. Civil Engineering, 56, 73-78. http://dx.doi.org/10.3311/pp.ci.2012-1.08

[58] Agrawal, S.K. and Henry, J.J. (1977) Technique for Evaluating Hydroplaning Potential of Pavements. Transportation Research Record, No. 633, 1-7.

[59] Miller, M. and Johnson, H. (1973) Effect of Resistance to Skidding on Accidents Surface Dressing on Elected Surface of M4 Motorway. Transport and Road Research Laboratory, Report LR542.

[60] Kamel, N. and Gartshore, T. (1982) Ontario's Wet Pavement Accident Reduction Program. ASTM Special Technical Publications, West Conshohocken, 98-117.

[61] OECD (1984) Road Surface Characteristics-Their Interaction and Their Optimization. OECD Scientific Expert Group, Road Transport Research, Paris.

[62] Roe, P., Webster, D. and West, G. (1991) The Relation between the Surface Texture of Roads and Accidents.

[63] Wambold, J.C., Henry, J.J. and Hegmon, R.R. (1986) Skid Resistance of Wet-Weather Accident Sites. The Tire Pavement Interface, ASTM STP 929. ASTM International, West Conshohocken, 47-60. http://dx.doi.org/10.1520/STP20001S

[64] Schulze, K., Gerbaldi, A. and Chavet, J. (1977) Skidding Accidents, Friction Numbers, and the Legal Aspects Involved Report of the PIARC Technical Committee on Slipperiness and Evenness. Transportation Research Record, No. 623, 1-10.

[65] Gothie, M. (1996) Relationship between Surface Characteristics and Accidents. International Symposium on Pavement Surface Characteristics, Christchurch,3-4 September 1996, 271-282.

[66] Bray, J. (2002) The Role of Crash Surveillance and Program Evaluation: NYSDOT's Skid Accident Reduction Program (SKARP). 28 th International Forum on Traffic Records and Highway Information Systems, Orlando, 4-8 August 2002.

[67] McLean, J. (1995) The Relationship between Pavement Conditions and Road Safety. LoadPavement Interaction Workshop 1995, Newcastle, 5-6 July 1995, 7 p.

[68] Larson, R. (1999) Consideration of Tire/Pavement Friction/Texture Effects on Pavement Structural Design and Materials Mix Design. Office of Pavement Technology, HIPT.

[69] West, T., et al. (2001) Evaluation of Dolomite and Related Aggregates Used in Bituminous Overlays for Indiana Pavements. Transportation Research Record: Journal of the Transportation Research Board, 1757, 137-147.

[70] Goodman, S., Hassan, Y. and El Halim, A. (2006) Preliminary Estimation of Asphalt Pavement Frictional Properties from Superpave Gyratory Specimens and Mix Parameters. Transportation Research Record: Journal of the Transportation Research Board, 1949, 173180.

[71] Whitehurst, E.A. and Goodwin, W. (1955) Pavement Slipperiness in Tennessee. Highway Research Board Proceedings, Washington DC, 11-14 January 1955, Vol. 34.

[72] Gray, J. and Renninger, F. (1966) The Skid-Resistant Properties of Carbonate Aggregates. Highway Research Record, No. 120, 18-34. 
[73] Nichols, F., Dillard, J.H. and Alwood, R. (1956) Skid Resistant Pavements in Virginia. Highway Research Board Bulletin, No. 139, 35-59.

[74] Balmer, G.G. and Colley, B. (1966) Laboratory Studies of the Skid Resistance of Concrete. Journal Materials, 1, 536-559.

[75] Csathy, T., Burnett, W. and Armstrong, M. (1968) State of the Art of Skid Resistance Research. Highway Research Board Special Report, No. 95, 34-48.

[76] Moore, D.F. (1969) Recommendations for an International Minimum Skid Resistance Standard for Pavements.

[77] Shupe, J. (1960) Pavement Slipperiness. McGraw-Hill Book Company, New York.

[78] McDaniel, R.S. and Coree, B.J. (2003) Identification of Laboratory Techniques to Optimize Superpave HMA Surface Friction Characteristics.

[79] Kowalski, K.J. (2007) Influence of Mixture Composition on the Noise and Frictional Characteristics of Flexible Pavements. ProQuest.

[80] Cairney, P. (1997) Skid Resistance and Crashes: A Review of the Literature.

[81] Roe, P., Parry, A. and Viner, H. (1998) High and Low Speed Skidding Resistance: The Influence of Texture Depth.

[82] Wambold, J.C. and Henry, J. (1994) International Piarc Experiment to Compare and Harmonize Texture and Skid Resistance Measurement. Nordic Road and Transport Research, 6, 28-31.

[83] Kokot, D. (2005) Evaluating Skidding Resistance in Slovenia. Slovenian National Building and Civil Engineering Institute.

[84] Henry, J.J. (2000) Evaluation of Pavement Friction Characteristics. Vol. 291, Transportation Research Board.

[85] Saito, K., et al. (1996) Development of Portable Tester for Measuring Skid Resistance and Its Speed Dependency on Pavement Surfaces. Transportation Research Record: Journal of the Transportation Research Board, 1536, 45-51.

[86] Fwa, T., Choo, Y. and Liu, Y. (2003) Effect of Aggregate Spacing on Skid Resistance of Asphalt Pavement. Journal of Transportation Engineering, 129, 420-426. http://dx.doi.org/10.1061/(ASCE)0733-947X(2003)129:4(420)

[87] Liu, Y., Fwa, T. and Choo, Y. (2004) Effect of Surface Macrotexture on Skid Resistance Measurements by the British Pendulum Test. Journal of Testing and Evaluation, 32, 304309. http://dx.doi.org/10.1520/JTE11428

[88] Forde, M., Birse, R. and Fraser, D. (1976) An Assessment of British Pendulum Based Methods of Skid Resistance Evaluation Using Schonfeld's Photo-Interpretation Method. Australian Road Research Board Conference Proceedings, University of Western Australia, 23-27 August 1976, 29-35.

[89] Salt, G.F. (1977) Research on Skid-Resistance at the Transport and Road Research Laboratory (1927-1977). Transportation Research Record, No. 622, 26-38.

[90] Purushothaman, N., Heaton, B. and Moore, I. (1988) Experimental Verification of a Finite Element Contact Analysis. Journal of Testing and Evaluation, 16, 497-507. http://dx.doi.org/10.1520/JTE11268J

[91] Abe, H., et al. (2001) Measurement of Pavement Macrotexture with Circular Texture Meter. Transportation Research Record: Journal of the Transportation Research Board, 1764, 201 209.

[92] Yandell, W., Taneerananon, P. and Zankin, V. (1983) Prediction of Tire/Road Friction 
from Surface Texture and Tread Rubber Properties. Frictional Interaction of Tire and Pavement. American Society for Testing and Materials, West Conshohocken, 304-322.

[93] Leland, T.J., Yager, T.J. and Joyner, U.T. (1968) Effects of Pavement Texture on Wet-Runway Braking Performance. Vol. 4323, National Aeronautics and Space Administration.

[94] Henry, J. and Hegmon, R. (1975) Pavement Texture Measurement and Evaluation. ASTM Special Technical Publication, West Conshohocken, 3-17. http://dx.doi.org/10.1520/stp39040s

[95] Moore, D.F. (1966) Prediction of Skid-Resistance Gradient and Drainage Characteristics for Pavements. Highway Research Record, No. 131, 181-203.

[96] Walker, R. and Payne, L. (Undated) Use of Selcom Laser for Pavement Texture and Skid Resistance Measurement. Research Project, No. 1290, Transportation Instrumentation Laboratory, University of Texas, Arlington.

[97] Her, I., Henry, J.J. and Wambold, J.C. (1984) Development of a Data Acquisition Method for Noncontact Pavement Macrotexture Measurement.

[98] McGhee, K.K. and Flintsch, G.W. (2003) High-Speed Texture Measurement of Pavements.

[99] Hanson, D.I. and Prowell, B.D. (2004) Evaluation of Circular Texture Meter for Measuring Surface Texture of Pavements. NCAT Report, 04-05.

[100] Williams, A.R. and Lees, G. (1970) Topographical and Petrographical Variation of Road Aggregates and the Wet Skidding Resistance of Tyres. Quarterly Journal of Engineering Geology and Hydrogeology, 2, 217-236. http://dx.doi.org/10.1144/GSL.QJEG.1970.002.03.04

[101] Tourenq, C. and Fourmaintraux, D. (1971) Road Surface Roughness and the Properties of Aggregates. Bulletin de Liaison des Laboratoires des Ponts et Chausses, 51, 61-69.

[102] Do, M.T. and Marsac, P. (2002) Assessment of the Polishing of the Aggregate Microtexture by Means of Geometric Parameters. TRB 81st Annual Meeting, Transportation Research Board, France, January 2002, 19 p.

[103] Won, M. and Fu, C. (1996) Evaluation of Laboratory Procedures for Aggregate Polish Test. Transportation Research Record: Journal of the Transportation Research Board, 1547, 2328.

[104] Samuels, S.E. (1986) The Feasibility of Measuring Road Surface Microtexture by Means of Laser Techniques.

[105] Schonfeld, R. (1974) Photo-Interpretation of Pavement Skid Resistance in Practice. Transportation Research Record, 523, 65-75.

[106] Schonfeld, R. (1970) Photo-Interpretation of Skid Resistance. Highway Research Record, No. 311, 11-25.

[107] Gransberg, D.D., Karaca, I. and Burkett, W.R. (2002) Quantifying Seal Coat Surface Condition Using Digital Image Processing Based on Information Theory. International Journal of Pavement Engineering, 3, 197-205. http://dx.doi.org/10.1080/1029843021000101693

[108] Pidwerbesky, B.D. Waters, J., Gransberg, D., Stemprok, R. and Land Transport New Zealand (2006) Road Surface Texture Measurement Using Digital Image Processing and Information Theory.

[109] Masad, E., et al. (2005) Test Methods for Characterizing Aggregate Shape, Texture, and Angularity. Technical Report, National Cooperative Highway Research Program-NCHRP.

[110] Araujo, V.M., Bessa, I.S. and Branco, V.T.C. (2015) Measuring Skid Resistance of Hot Mix Asphalt Using the Aggregate Image Measurement System (AIMS). Construction and Building Materials, 98, 476-481. http://dx.doi.org/10.1016/j.conbuildmat.2015.08.117 